\title{
БОТАНИК В.Н. СУКАЧЕВ И РАЗВИТИЕ ИДЕЙ Ч. ДАРВИНА В РОССИИ Я.М. Галл
}

Санкт-Петербургский филиал Института истории естествознания и техники им. С.И. Вавилова РАН Эл.noчma: Gall1946@mail.ru

Статья поступила в редакцию 18.01.2016; принята к печати 22.02.2016

Дарвиновские концепции борьбы за существование и естественного отбора широко обсуждались в Российских академических и публичных кругах, начиная со второй половины XIX - первой четверти XX столетия. Кроме дарвиновской интерпретации борьбы за существование и естественного отбора сложились и другие конкурирующие теории. Решить проблему можно было лишь одним путем. Требовалось создать экспериментальные модели, которые подтвердили или внесли коррекцию в теорию Дарвина. Задача статьи состоит в анализе экспериментальных исследований борьбы за существование и естественного отбора, развитые российским ботаником В.Н. Сукачевым в 1920-1950-е годы.

Ключевые слова: Владимир Николаевич Сукачев, экспериментальные модели, борьба за существование, естественный отбор, эволюционная теория в России.

\section{THE BOTANIST V.N. SUKACHEV AND THE DEVELOPMENT OF DARWIN'S IDEAS IN RUSSIA Ya.M. Gall}

Saint Petersburg Branch of the Institute for the History of Science and Technology of the Russian Academy of Science. Saint Petersburg. Russia E-mail: Gall1946@mail.ru

Darwin's concepts of the struggle for existence and natural selection were widely discussed in Russian academic and public press in the second half of the nineteenth century through the first quarter of the twentieth century. Apart from Darwin's interpretation of the struggle for existence and natural selection, a number of competing theories emerged. There was only one way to solve this problem. It was necessary to develop experimental models that could confirm or correct Darwin's theory. The present paper aims to review the experimental research on the struggle for existence and natural selection developed by Russian botanist V.N. Sukachev in the 1920-1950.

Keywords: Vladimir Nikolayevich Sukachev, experimental models, struggle for existence, natural selection, evolutionary theory in Russia.

Жизни и научной деятельности академика Владимира Николаевича Сукачева (1880-1967) посвящена специальная книга С.В. Зонна - крупного почвоведа, участника многих экспедиций Сукачева [2]. В книге очень ярко и подробно освещена деятельность Сукачева в различных областях лесоведения, фитоценологии, биоценологии и лесной биогеоценологии. Раздел же об общебиологических воззрениях Сукачева написан очень кратко, практически без анализа его экспериментальных работ.

Цель данной статьи - кратко показать огромный вклад, который Владимир Николаевич внес в развитие дарвиновой теории эволюции, защите дарвинизма в нашей стране. Быть может, самое главное состоит в том, что Сукачев принадлежит к числу основоположников экспериментального изучения борьбы за существование и естественного отбора и благодаря экспериментальным работам стал классиком эволюционной теории. Обычно еще добавляют: «классик мирового масштаба». А других классиков просто не бывает.

В эволюционной теории Ч. Дарвина механизм действия естественного отбора основан на случайных вариациях, наследственности и борьбе за существование. Однако Дарвин не имел реальных доказательств того, как борьба за существование ведет к естественному отбору. Вообще во второй половине XIX - первой четверти XX века не было солидных доказательств механизмов эволюции, хотя исторический метод в биологии уже широко применялся. Удивительно, солидных доказательств не было, но

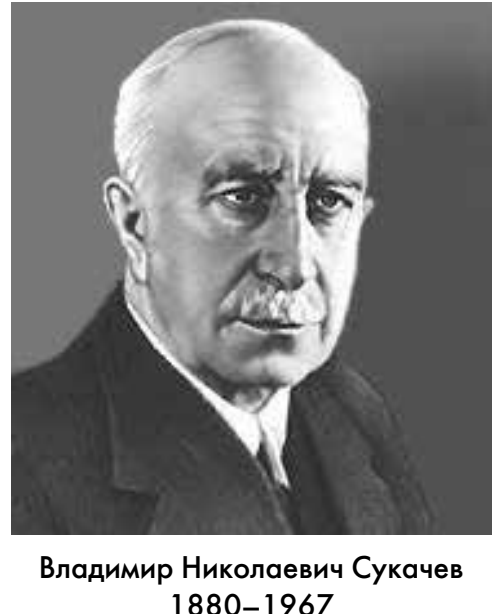

сама идея борьбы за существование широко обсуждалась учеными, писателями, публицистами, политическими деятелями и даже юристами. В результате широких дискуссий три другие недарвиновские интерпретации борьбы за существование сложились в научной литературе.

Борьба за существование признавалась консервативным фактором, так как результатом ее является отбор, лишь охраняющий адаптивную норму вида (С. Майварт, Н.Я. Данилевский, Л.С. Берг и другие ученые).

Были биологи и географы, считавшие, что борьба за существование внутри вида - фактор, ведущий 
к взаимному угнетению организмов (депрессивный фактор) и даже к тотальной гибели организмов (К. Нэгели, П.А. Кропоткин, В.Н. Любименко).

Отстаивались мысли, что внутривидовая конкуренция в природе отсутствует. Борьба за существование происходит только между видами, и в результате случайно выживают виды, а вовсе не лучше приспособленные особи. Борьба за существование не является фактором естественного отбора. Она лишь распределяет уже готовые «адаптивные формы» по ареалу (Г. де-Фриз).

Все эти гипотезы о роли борьбы за существование казались тогда равновероятными. Но все очевиднее становилось мнение, что общими разговорами об эволюционной роли борьбы за существование проблему никогда не решить. Требовалось перейти к систематическим экспериментальным исследованиям [1].

Для эволюционной теории Дарвина требовалось добыть реальные факты, доказывающие, что в результате борьбы за существование происходит избирательная элиминация и в особенности элиминация, ведущая к сдвигу адаптивной нормы вида. Требовалось также доказать, что решающая роль в борьбе за существование может принадлежать мелким вариациям или индивидуальным различиям и, что немаловажно, эти генетические факторы, как теперь говорят, носят наследственный характер. Почему так важно подчеркнуть «наследственный характер»? Еще Дарвин обратил внимание на то, что отбор по ненаследственным изменениям малоэффективен, так как весь его «накопительный» арсенал просто пропадает в следующих поколениях.

Переход от спекуляций к серьезной экспериментальной работе требовал времени. Но почему требовалось время? Ведь проблема конкуренции в растительных сообществах уже детально изучалась в США Фредериком Клементсом и его огромной школой на протяжении 1920-1930-х гг. [12, 13, 14]. Однако американские ученые не изучали эволюционные аспекты проблемы конкуренции среди высших растений. В 1909 г. Клементс опубликовал юбилейную статью под названием «Влияние Дарвина на географию растений и экологию» [11]. По этой статье хорошо видно, что Клементс в идейном плане оставался «в плену» старых идей, которые доминировали в естественной истории и в естественной теологии (У. Пэйли) до Дарвина. В частности, он писал, что Дарвин не внес ничего нового в идею борьбы за существование по сравнению с Ч. Лайелем. Вполне серьезно в упомянутой статье на второй странице Клементс писал, что экспериментальный эколог без сомнения будет следовать за Дарвином в отношении наследования приобретаемых признаков. Когда читаешь тома школы Клементса по растительной конкуренции, то впечатление возникает двойственное. Затрачен огромнейший труд экспериментальной работы в поле, питомниках, вегетационных домиках и сосудах. Накоплен огромный фактический материал. А зачем? Ведь никакой руководящей идеи в этих томах просто нет. Горы фактов и литературных источников у Клементса просто не повязаны какой-либо руководящей идеей.

Сукачев был ведущим среди ботаников и биологов, кто начал изучать борьбу за существование и естественный отбор экспериментальными методами, опираясь не только на экологию растений, но и на генетику. По сути дела, его экспериментальные работы были пионерскими не только в области эволюционной теории, но и в той области, которая сейчас носит название «популяционная биология». Его главным учителем, который приложил дарвинизм к лесоводству, был Георгий Федорович Морозов. Он сумел в начале XX в., когда теория Дарвина переживала глубокий кризис, показать практическую значимость теории Дарвина. Он использовал популярную таблицу Крафта и метод глубокой траншейной изоляции корней у сомкнутого древостоя, впервые предложенный швейцарским лесоводом К. Фрике в 1904 г., но о котором многие ботаники и лесоводы просто забыли, а его метод был возрожден школой Сукачева и по сей день является основным в экспериментальной лесной фитоценологии [1].

В начале 20-х гг. ХХ столетия А.П. Шенников и В.Н. Сукачев $[5,10]$ предложили исследовательские программы по экспериментальной фитоценологии. По мнению выдающихся ботаников, центральной задачей экспериментальной фитоценологии должно стать изучение дарвиновой борьбы за существование.

Сукачев предлагал два возможных пути экспериментального изучения борьбы за существование. Первый - создание одновидовых и смешанных насаждений с целью выяснить действие на процессы борьбы за существование - порознь и в комбинации таких факторов, как плотность, качественный состав популяции, особенности почвы, климата, освещенности. Второй - работы в естественной обстановке, путем изменений условий среды или видового состава сообщества.

В круг эволюционных вопросов борьбы за существование, решение которых требовало применения экспериментального метода, Сукачев включал изучение величины и характера элиминации в зависимости от действия различных биотических и абиотических факторов, установление селективной роли мелких мутаций и индивидуальных различий, влияние плотности популяции на индивидуальное развитие.

Чтобы установить общие закономерности борьбы за существование, Сукачев считал важным использовать в опытах как однолетники, так и многолетники. При этом удобнее всего начинать исследования с искусственных популяций самоопыляющихся растений, состоящих из нескольких чистых линий, биотипов-клонов, а затем переходить к изучению борьбы за существование в природных популяциях перекрестноопыляющихся растений. Важным средством в этих исследованиях, по мнению Сукачева, должно стать использование биометрических методов для изучения изменчивости морфологических признаков в условиях различных плотностей стояния растений. Вполне очевидно, что Сукачев предлагал внедрять в фитоценологию биометрическую генетику. Позднее, подводя итоги своим экспериментам на ивах, Сукачев указал на плодотворность союза фитоценологов и биологов-эволюционистов, сложившегося на основе изучения борьбы за существование. Он также отметил научную ценность дарвиновой идеи борьбы за существование, и в настоящее время являющуюся теоретической основой развития фитоценологии и эволюционной теории [9].

Разумеется, реализовать такую обширную научную программу можно было лишь при наличии школы или группы способных единомышленников. Вместе с Сукачевым в важнейших фитоценологиче- 
ских исследованиях приняли участие В.Б. Сочава, Л.И. Успенская в Ленинграде, Е.А. Смирнова в Москве, В.П. Кушниренко в Полтаве, София Закарян в Баку.

Но для целей настоящего исследования представляются наиболее важными оригинальные исследования самого Владимира Николаевича, так как они были нацелены на решение фундаментальных проблем не только фитоценологии, но и эволюционной теории.

По намеченной программе Сукачев в 1924 г. начал экспериментальные исследования эволюционных следствий борьбы за существование. Базой этих исследований послужили опытные питомники Ленинградского лесного института и Ленинградского сельскохозяйственного института. Позднее опыты были продолжены в Петергофском биологическом институте Ленинградского университета. Пионерской и наиболее важной была экспериментальная работа Сукачева с обыкновенным одуванчиком (Taraxacum officinale). Он изучал шесть биотипов одуванчика различного географического происхождения при двух плотностях экспериментальной популяции. Было четко установлено, что биотип на удобренных почвах при конкуренции между особями одного биотипа оказывался менее адаптивным, чем при конкуренции между биотипами. При этом «мигранты» из Вологды и Архангельска при принятых в опытах высоких плотностях часто обладали большей выживаемостью, чем местные биотипы.

Выживаемость - важнейший показатель в популяционных исследованиях, но всегда нужно проверить «победителей» на плодовитость, если исследователь желает получить эволюционно значимый результат. Дарвинова теория естественного отбора и адаптации основывалась именно на таком постулате. Поэтому следующим этапом в экспериментах Сукачева стало изучение репродуктивных способностей выживших биотипов. Он со всей эволюционно-биологической прозрачностью писал: «Мыслим случай, когда известный биотип сохраняет в борьбе за существование значительное число своих особей, но крайне угнетенных, неспособных даже оставить потомство, а с другой стороны, небольшое число уцелевших экземпляров другого биотипа может быть удовлетворительно развитым и плодоносящим» [6, с. 202]. Сукачев однозначно показал, каким образом меняется адаптивная ценность генотипов при различных плотностях популяции, причем конкуренция между биотипами составляет основу для действия естественного отбора.

Сукачев впервые использовал в фитоценологии метод клонирования биотипов с целью изучения генетических различий между биотипами по конкурентной приспособленности. При этом использовались биотипы различного географического происхождения, что позволило выявить роль почвенных, ценотических и генетических факторов в процессе естественного отбора. Внедрение генетических методов в экологию сообществ привело к сравнительному изучению физиологических и генетических особенностей клоновбиотипов, экспериментально вовлеченных во внутривидовую и межвидовую конкуренцию.

Но Сукачев не полностью отвергал концепцию известного ботаника и физиолога растений В.Н. Любименко о всеобщем угнетении и гибели растений в борьбе за существование [3]. Он хотел проверить гипотезу именитого ученого, но его данные этого не подтверждали, во всяком случае, для тех плотностей популяций, с которыми он реально работал. Сукачев открыл, что конкурентная приспособленность всегда включает два признака: выживаемость и репродукцию, и эти две характеристики особей и популяций не всегда совпадают. Сейчас это школьная грамота по популяционной биологии, но кто-то же должен был придумать удовлетворительный эксперимент и реально все это показать.

Опыты Сукачева показали и то, как мало мы знаем о факторах эволюции, действующих в экспериментальных и природных популяциях. В статье 1935 г., в которой был изложен новый экспериментальный материал, Сукачев особо отметил необходимость широкого развертывания исследований борьбы за существование как фактора эволюции, так как «до сих пор о роли борьбы за существование между растениями как в процессе видообразования, так и в жизни фитоценозов говорилось лишь на основании априорных суждений» [7, с. 70]. Он значительно расширил исследования, включив на всю мощность биометрическую генетику. Для новых экспериментов Владимир Николаевич выбрал овсяницу луговую (Festuca sulcata Hack. Nym). Сейчас систематики луговых растений почему-то называют ее бороздчатой. Видимо, у систематиков мало работы, и точно характеризуемый вид превратился в слабо понятный вид по определению.

Мысли о том, что настала совершенно новая эра в развитии эволюционной теории и фитоценологии, буквально захватили Владимира Николаевича полностью. К опытам с овсяницей он готовился очень тщательно. В 1923 г. Сукачев при посещении Аскании-Нова обратил внимание на разнообразие произрастающих здесь биотипов овсяницы. Он собрал семена отдельных ее форм и высеял их на следующий год в ботаническом саду Лесного института. В 1928 г. самые крупные кусты трех различных биотипов были отобраны, и в течение последующих двух лет путем их разделения (клонирование) Сукачев получил много генетически однородных кустов. В 1931 г. этот чистый в генетическом отношении материал был использован для опытов по конкуренции и естественному отбору. Здесь отметим лишь важнейшие моменты. Как и в опытах с одуванчиком, Сукачев четко показал, что борьба за существование и естественный отбор играют решающую роль в образовании собраний биотипов (экотипов) и все эти процессы вовлечены в видообразование. Метод клонирования позволил Сукачеву обнаружить у растений генетические различия в реакции на плотность. С ростом плотности популяции нивелировка растений не только не наблюдается, но происходит совершенно иное - рост генетических различий, то есть увеличивается дифференциация растений. Высокие плотности популяций представляют собой хороший фон, когда интенсивная конкуренция увеличивает и интенсивность действия естественного отбора.

Сукачев очень ясно показал, что внутривидовая конкуренция ведет к естественному отбору, и малые биотипические различия достаточны для его эффективности. Таким образом, были изучены некоторые модели микроэволюционных трансформаций. Безусловно, эксперименты Сукачева с одуванчиком и 
овсяницей опровергали недарвиновские интерпретации эволюционного значения борьбы за существование в области принятых плотностей экспериментальных популяций. Это было особенно важным, так как в то время генетика и экология были еще изолированными друг от друга, и эксперименты Сукачева четко показали пути интеграции при экспериментальном изучении эволюции. Работа Сукачева 1927 г. была переведена в Германии и быстро привлекла внимание крупнейших генетиков и биологов-эволюционистов [19]. Дж.Б.С. Холдейн и Дж. Хаксли рассматривали эксперименты Сукачева в качестве самых лучших доказательств механизмов действия естественного отбора $[16,17]$. Ученые обратили внимание на то, что после экспериментов Владимира Николаевича теория естественного отбора стала превращаться в строгую теорию с экспериментальным базисом.

Ф. Добржанский в своей знаменитой книге «Генетика и происхождение видов», изданной в 1937 г., посвятил Сукачеву целый параграф и цитировал оригинальные русские тексты [15].

Таким образом, упомянутые концепции Г. де-Фриза и Л.С. Берга были фальсифицированы: концепции отрицали реальность внутривидовой конкуренции или рассматривали борьбу за существование только в качестве консервативного фактора. Но эволюционно-биологическая реальность оставалась все же сложной. Дарвинизму приходилось еще очень трудно при интерпретации данных о массовом угнетении многолетних растений при высоких плотностях популяции. Нелегко было объяснить, почему не было массовой элиминации и стерилизации однолетников при таких же высоких плотностях.

Все эти нерешенные вопросы побудили Сукачева выполнить новую серию экспериментов с однолетними и многолетними растениями. Результаты этих исследований были опубликованы в небольшой, но очень принципиальной статье [8]. По сути дела, в статье ставились вопросы, которые в современной науке звучат так: факторы эволюции и индивидуальное развитие на популяционном уровне. Владимир Николаевич экспериментально показал, что эффекты интенсивной борьбы за существование различны на уровне индивидуального развития однолетников и многолетников. При интенсивной борьбе за существование однолетники стремятся быстро пройти все фазы развития, которые должны закончиться плодоношением. У многолетников, наоборот, процессы индивидуального развития резко замедляются, и они уходят под снег в недоразвитом состоянии. Таким способом многолетники переживают неблагоприятные условия, а при улучшении внешних условий наступает фаза нормального развития и плодоношения. Без всяких сомнений, по мнению Сукачева, такие противоположные реакции носят адаптивный характер. Это правило было подтверждено высадкой однолетников «на свободу» без давления высокой плотности популяций. В этих обычных условиях все растения нормально развивались и плодоносили.

Вне всяких сомнений, можно сказать, что Сукачев ясно показал всю слабость воззрений ботаников, включая и В.Н. Любименко, которые стремились опровергнуть идеи Дарвина о борьбе за существование и естественном отборе экспериментальными методами. Ботаники просто не владели методами эволюционно-популяционных исследований. Без популяционно-эволюционного подхода вся проблема индивидуального развития представляла собой черный ящик. Сукачев привнес в него очень много света. Но новаторские идеи Сукачева практически не были восприняты долгое время ни в России, ни за ее пределами. Кроме того, началась Великая Отечественная война, а после войны и возрастающее влияние Т.Д. Лысенко, который отрицал не только эволюционную роль внутривидовой конкуренции, но и ее реальность. Лишь К.М. Завадский и Т.А. Работнов поддержали и развивали идеи Сукачева в этой сложной области эволюционной теории и фитоценологии.

Все исследования Сукачева велись в направлении экспериментального изучения эволюционной роли внутривидовой конкуренции. Но в природных фитоценозах имеет место сложное взаимодействие внутри- и межвидовой конкуренции. В зависимости от экологической ситуации направление действия естественного отбора может резко меняться, внутривидовая конкурентная приспособленность не гарантирует выживание популяции при мощном прессе межвидовой конкуренции. Требовалось сконструировать эксперименты, доказывающие различия особей в популяции по внутривидовой и межвидовой конкурентной приспособленности.

Для исследования Владимир Николаевич выбрал ивы. Это было не случайно. Многие годы после работы он отдыхал, занимаясь систематикой ив. Материал он знал очень хорошо и даже готовил учеников в области систематики ив (А.К. Скворцов).

Сукачев выполнил оригинальные исследования по сравнительной оценке внутривидовой и межвидовой конкурентной приспособленности биотипов двух видов ив (Salix viminalis и S. purpurea) [9]. Методика Сукачева заключалась в посадке черенков двух видов на делянках с разными площадями питания - $36 \times 36$, $18 \times 18$ и $9 \times 9$ см. В смешанных посадках ряды биотипов различных видов чередовались. Мерилом интенсивности борьбы за существование служил средний прирост длины всех прутьев с растения. Опыты Сукачева показали, что в чистых редких посадках прутьевидная ива росла лучше, чем пурпурная. Однако эти различия в росте не проявились в чистых загущенных посадках $(18 \times 18 \mathrm{~cm})$.

Совсем иная картина наблюдалась Сукачевым в чистых и в смешанных посадках с площадью питания $9 \times 9$ см. В чистых посадках у прутьевидной ивы явно снизился прирост прута, в то время как у пурпурной ивы не обнаружилось реагирование на рост плотности популяции. В смешанных же посадках шли противоположные процессы: пурпурная ива значительно хуже развивалась, чем в чистых посадах, а у прутьевидной ивы не снижался прирост. Обнаружив различное поведение видов в борьбе за существование, Сукачев поставил проверочные опыты. Один экземпляр каждого из видов он окружил на расстоянии 15 и 20 см двумя рядами экземпляров разных видов. Такое положение особей уже полностью гарантировало для серединного экземпляра влияние особей в одном случае того же вида, а в другом - конкурента. Результаты предыдущего опыта подтвердились.

Таким образом, работая с биотипами, Владимир Николаевич показал, что существуют генетические различия между внутривидовой и межвидовой конкурентной приспособленностью. Кроме того, на древесных растениях было подтверждено положе- 
ние, что приспособленность биотипов зависит от состава и плотности популяций. Эта серия опытов представляла первую попытку оценить генотипы по внутривидовой и межвидовой конкурентной приспособленности. В этом отношении опыты Сукачева открывали новые возможности в развитии теории эволюции, фитоценологии и популяционной биологии. Реальные фитоценозы формируются в результате интегрального действия борьбы за существование и естественного отбора. В природных популяциях в зависимости от экологического фона, климата, типа почвы постоянно идет переоценка адаптивной ценности генотипов, слагающих не только отдельные популяции, но и весь фитоценоз.

В 70-е гг. ХX столетия благодаря экспериментальной активности Михаила-Иосифа Лернера в США было выполнено много прекрасных работ на Drosophila и Tribolium, подтверждающих основополагающий вывод Сукачева.

Крупнейший ботаник-эволюционист Дж. Стеббинс назвал экспериментальные работы Сукачева важнейшими в области изучения естественного отбора у растений [18].

По личному убеждению автора настоящей статьи, трудно и не надо сравнивать экспериментально-ботанические работы эволюционного плана, выполненные популяционными биологами, физиологами или биохимиками, с великолепной серией работ Сукачева. Удивительно, но он всегда опережал время в масштабах мировой науки. Можно сожалеть лишь об одном. Владимир Николаевич не собрал свою великолепную экспериментальную серию в монографию и не перевел ее на английский язык. Есть хороший пример того, что это действительно нужно было сделать. В разговоре с Георгием Францевичем Гаузе я спросил: почему так широко цитируется ваша знаменитая книга «Борьба за существование», а не отдельные статьи, в которых изложен весь экспериментальный материал? Он, как всегда, ответил коротко и ясно. Эффект книги совершенно иной, чем воздействие отдельных статей.

Быть может, Владимиру Николаевичу помешало тяжелое время. После разгрома генетики, будучи уже в пожилом возрасте, Сукачев возглавил фронт борьбы с псевдонаукой. Уже с 1946 г. Сукачев постоянно выступал с критическими публикациями по вопросу о внутривидовой конкуренции и естественном отборе, прямо направляя свои работы против Лысенко. Он создал серию работ, направленных против псевдонауки в целом. В 1950-е гг. Сукачев как главный редактор «Ботанического журнала» и «Бюллетеня МОИП» много сделал для защиты, пропаганды и развития теории Дарвина в нашей стране. В Москве люди самых разных специальностей выстраивались в очереди в книжные магазины и киоски, надеясь приобрести «Бюллетень МОИП», зная, что в нем всегда есть материалы против Лысенко (личное сообщение В.В. Алпатова).

\section{Литература}

\section{Список русскоязычной литературы}

1. Галл ЯМ. Борьба за существование как фактор эволюции. Л.: Наука, 1976.

2. Зонн СВ. Владимир Николаевич Сукачев: 1880-1967. М.: Наука, 1987.

3. Любименко ВН, Щеглова ОА, Булгакова ЗП. Опыты над соревнованием за место у растений. Журн. Русск. бот. об-ва. 1925;(10): 293-338.

4. Морозов ГФ. Учение о лесе. СПб.; 1912.

5. Сукачев ВН. Экспериментальная фитосоциология и ее задачи. Записки Ленинградского сельскохозяйственного ин-та. 1925;(2):174-86.

6. Сукачев ВН. К вопросу о борьбе за существование между биотипами одного и того же вида. В кн.: Юбилейный сборник, посвященный И.П. Бородину. Л.: Русское ботаническое об-во; 1927. с. 195-219.

7. Сукачев ВН. Опыт экспериментального изучения межбиотипной борьбы за существование у растений. Труды Петергофского биол. ин-та. 1935;(15):69-86.

8. Сукачев ВН. О влиянии интенсивности борьбы за существование между растениями на их развитие. Доклады АН СССР. 1941;30(8):752-5.

9. Сукачев ВН. Новые данные по экспериментальному изучению взаимоотношений растений. Бюлл. МОИП, отд. биол. 1959;64(4):35-46.

10. Шенников АП. Фитосоциология и опытные питомники. Журнал Петроградского агрономического об-ва. 1921;(3-4):34-45.
Общий список литературы/Reference list

1. Gall YaM. Bor'ba za Sushchestvovaniye Kak Faktor Evolyutsii. Leningrad: Nauka; 1976. (In Russ.)

2. Zonn SV. Vladimir Nikolaevich Sukachev: 1880-1967. Moscow: Nauka; 1987. (In Russ)

3. Lubimenko VN, Sheglova OA, Bulgakova ZP. Opyty nad sorevnovaniem za mesto u rastenii. [Experimental studies of competition for place among plants]. Zhurnal Russkogo Botanicheskogo Obschestva.1925;10(3-4):293-338. (In Russ.)

4. Morozov GF. Ucheniye o Lese. Saint Petersburg; 1912. (In Russ.)

5. Sukachev VN. Eksperimental'naya fitosotsiologiya i ee zadachi. [Experimental phytosociology and its objectives]. Zapiski Leningradskogo Sel'skokhoziaystvennogo Instituta. 1925;(2):17486. (In Russ.)

6. Sukachev VN. K Voprosu o bor'be za sushchestvovaniye mezhdu biotipami odnogo i togo zhe vida. [On struggle for existence between the biotypes of a defined species]. Yubileynyi Sbornik Posvyaschennyi I.P. Borodinu. Leningrad: Russkoye Botanicheskoye Obshchestvo; 1927. p. 195-219.

7. Sukachev VN. Opyt eksperimental'nogo izucheniya mezhbiotipnoi bor'by za suschestvovaniye u rasteniy. [The experience of experimental studies of interbiotype struggle for existence in plants]. Trudy Petergofskogo Biologicheskogo Instituta Leningradskogo Universiteta. 1935;(15):69-86. (In Russ.) 
8. Sukachev VN. O vliyanii intensivnosti bor'by za sushchestvovaniye mezhdu rasteniyami na ikh razvitiye. [On the effect of the intensity of struggle for existence between plants on their development]. Doklady AN SSSR. 1941;30(8):752-5. (In Russ.)

9. Sukachev VN. Novye dannye po eksperimental'nomu izucheniyu vzaimootnosheniy rasteniy [Novel data from experimental studies of interrelationships between plants]. Bulleten’ MOIP Otdel Biol. 1959;64(4):35-46. (In Russ.)

10. Shennikov AP. Fitosotsiologiya i opytnye pitomniki [Phytosociology and experimental nursery-gardens]. Zhurnal Petrogradskogo Agronomicheskogo Obshchestva. 1921;(3-4):34-45.

11. Clements F. Darwin's influence upon plant geography and ecology. Amer Nat. 1909;53(507):148-9.

12. Clements F, Weaver J. Experimental Vegetation. Washington: Carnegie Institute; 1924.
13. Clements F, Weaver J, Hanson H. Plant Competition: An Analysis of Community Function. Washington: Carnegie Institute; 1929.

14. Clements F, Shelford V. Bio-Ecology. New York: Wiley; 1939.

15. Dobzhansky Th. Genetics and the Origin of Species, New York: Columbia University Press; 1937.

16. Haldane JBS. The Causes of Evolution. London: Longmans, Green and Co; 1932.

17. Huxley J. Evolution: The Modern Synthesis. London: George Allen and Unwin; 1942.

18. Stebbins G. Reality and efficacy of natural selection in plants. Proc Amer Phil Soc. 1949;93(6):501-13.

19. Sukachev VN. Einige experimentelle Untersuchungen über den Kampf ums Dasein zwischen Biotypen derselben Art. Zeitschrift für Induktive Abstammung und Vererbungslehre. 1928;47(1):54-74.

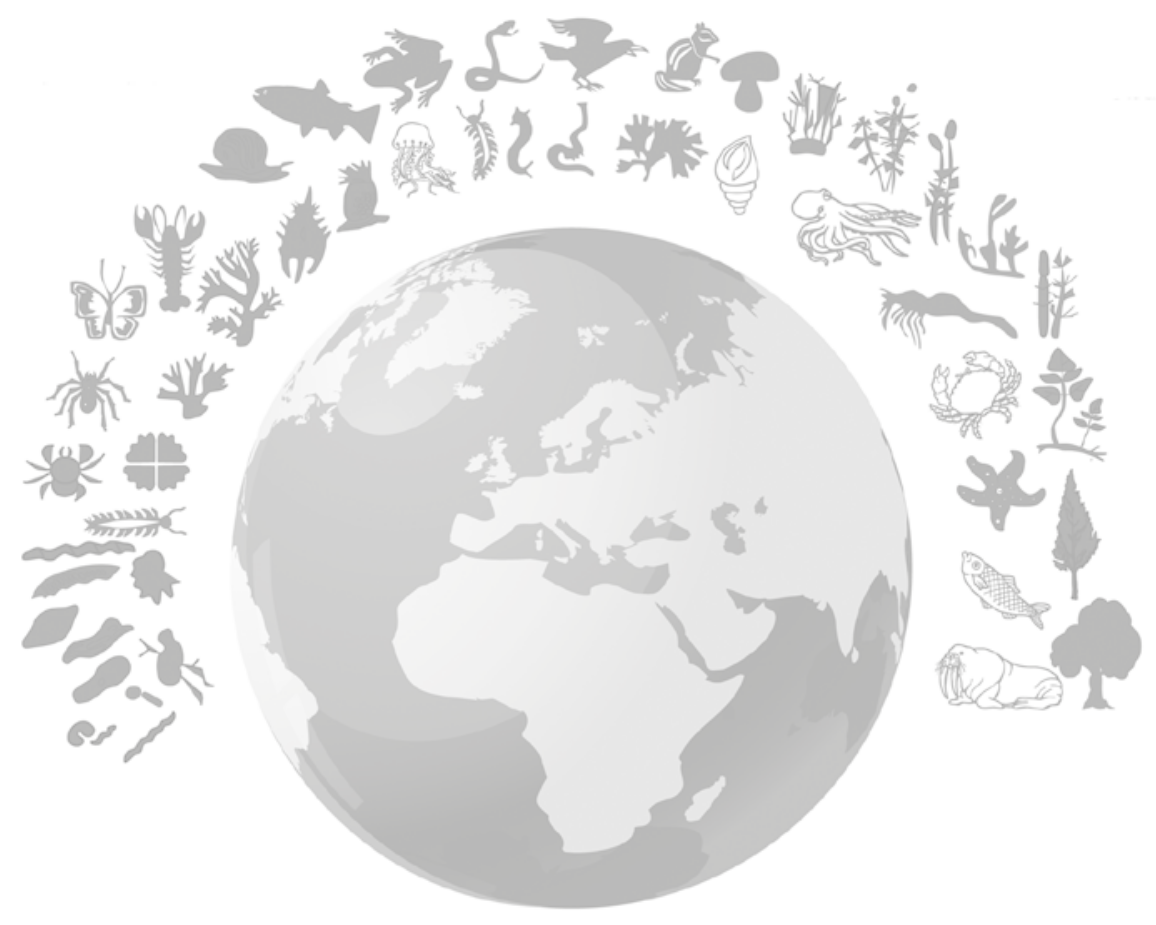

